Research

Open Access

\title{
Prevalence of sleep disturbances and long-term reduced health-related quality of life after critical care: a prospective multicenter cohort study
}

\author{
Lotti Orwelius ${ }^{1,2}$, Anders Nordlund 4 , Peter Nordlund5 5 , Ulla Edéll-Gustafsson² and Folke Sjöberg1,3
}

\author{
1'Department of Intensive Care, Division of Perioperative Medicine, Linköping University/Linköping University Hospital, Garnisonsvägen, 581 85, \\ Linköping, Sweden \\ 2Department of Medicine and Care, Nursing Science, Linköping University/Linköping University Hospital, Garnisonsvägen, 58185 Linköping, \\ Sweden \\ ${ }^{3}$ Department of Hand and Plastic Surgery, Division of Clinical and Experimental Medicine, Faculty of Health Sciences, Linköping University/Linköping \\ University Hospital, Garnisonsvägen, 58185 \\ 4TFS Trial Form Support AB, 22228 Lund, Sweden \\ ${ }^{5}$ Department of Anaesthesia and Intensive Care, Intensiv Care Unit, Ryhov Hospital, 55185 Jönköping, Sweden
}

Corresponding author: Lotti Orwelius, lotti.orvelius@lio.se

Received: 28 Mar 2008 Revisions requested: 13 May 2008 Revisions received: 5 Jun 2008 Accepted: 1 Aug 2008 Published: 1 Aug 2008

Critical Care 2008, 12:R97 (doi:10.1186/cc6973)

This article is online at: http://ccforum.com/content/12/4/R97

(c) 2008 Orwelius et al.; licensee BioMed Central Ltd.

This is an open access article distributed under the terms of the Creative Commons Attribution License (http://creativecommons.org/licenses/by/2.0), which permits unrestricted use, distribution, and reproduction in any medium, provided the original work is properly cited.

\begin{abstract}
Introduction The aim of the present prospective multicenter cohort study was to examine the prevalence of sleep disturbance and its relation to the patient's reported healthrelated quality of life after intensive care. We also assessed the possible underlying causes of sleep disturbance, including factors related to the critical illness.

Methods Between August 2000 and November 2003 we included 1,625 consecutive patients older than 17 years of age admitted for more than 24 hours to combined medical and surgical intensive care units (ICUs) at three hospitals in Sweden. Conventional intensive care variables were prospectively recorded in the unit database. Six months and 12 months after discharge from hospital, sleep disturbances and the healthrelated quality of life were evaluated using the Basic Nordic Sleep Questionnaire and the Medical Outcomes Study 36-item Short-form Health Survey, respectively. As a nonvalidated single-item assessment, the quality of sleep prior to the ICU period was measured. As a reference group, a random sample ( $n=10,000$ ) of the main intake area of the hospitals was used.

Results The prevalence of self-reported quality of sleep did not change from the pre-ICU period to the post-ICU period. Intensive care patients reported significantly more sleep disturbances than the reference group $(P<0.01)$. At both 6 and 12 months, the main factor that affected sleep in the former hospitalised patients with an ICU stay was concurrent disease. No effects were related to the ICU period, such as the Acute Physiology and Chronic Health Evaluation score, the length of stay or the treatment diagnosis. There were minor correlations between the rate and extent of sleep disturbance and the healthrelated quality of life.

Conclusion There is little change in the long-term quality of sleep patterns among hospitalised patients with an ICU stay. This applies both to the comparison before and after critical care as well as between 6 and 12 months after the ICU stay. Furthermore, sleep disturbances for this group are common. Concurrent disease was found to be most important as an underlying cause, which emphasises that it is essential to include assessment of concurrent disease in sleep-related research in this group of patients.
\end{abstract}

\section{Introduction}

Intensive care affects the patients in many ways, and also influences the outcome after discharge [1,2]. After a period in intensive care, patients have reported poorer health-related quality of life (HRQoL) compared with a reference group [3].
Furthermore, in a previous study we found that this poorer HRQoL is mostly the result of the high prevalence of concurrent disease among the patients rather than due to factors related to intensive care [4] 
Sleep is important for overall wellbeing [5]. In the short term, we know that many patients, irrespective of their diagnosis, have disturbed sleep during their time in the intensive care unit (ICU) and up to 1 week afterwards [6-9]. Former ICU patients may have more short-term sleep disturbances caused by both the period of critical care and the high prevalence of concurrent diseases [4]. Sleep-related problems may persist long after the patients have left the ICU. Because of the paucity of studies, however, the prevalence and extent of sleep disturbances that remain long term ( $>3$ months) after intensive care are unknown. A partly unanswered question is also the effect of sleep disturbances on HRQoL of former ICU patients. There is a difficulty in assessing sleep disturbances, as sleep varies with sex [10,11] and with age [11]. Sleep disturbance is also affected by concurrent diseases [12], so a reliable reference group is essential to be able to evaluate the prevalence of sleep disturbances properly.

The aim of the present study was to investigate the long-term (6-month and 12-month) sleep pattern after critical illness. We also wanted to examine specifically the relation between sleep disturbances and HRQoL. Furthermore, we wanted to know whether concurrent disease and factors related to intensive care (Acute Physiology and Chronic Health Evaluation (APACHE) II, length of stay, and admission diagnosis) affected the long-term sleep patterns in the ICU group.

We hypothesised that hospitalised patients with an ICU stay have an affected sleep long after the intensive care period has ended, but we suspected that it is the result of concurrent disease rather than of ICU-related factors.

\section{Materials and methods Design}

The present prospective, longitudinal study was carried out between August 2000 and November 2003 in three general ICUs in Sweden: one university hospital, and two general hospitals. The ICU at the university hospital has eight beds, and 500 to 750 patients are admitted annually. Postoperative patients, those after open-heart surgery and neurosurgery, those with primary coronary disease, neonates, and burned patients are treated in other specialised units, and were not included in the present study. The two general hospitals both have six-bed ICUs, and 500 to 700 patients are admitted annually to each. The units are the only ICUs at the hospitals except for the care of neonates. Over $90 \%$ of the admissions to these three ICUs are emergencies, and the primary admission diagnoses are most commonly multiple trauma, sepsis, and disturbances in the respiratory or circulatory systems, or both. All adults (18 years old and over) who were consecutively admitted and who remained in the ICU for more than 24 hours, and who were alive 6 months after discharge from hospital, were included. Patients who were readmitted were included only for their first admission. This database has previ- ously been used and will be used in several outcome studies in critical care [4].

The clinical databases in each hospital were used to extract data on age, sex, reason for admission to and length of stay in the ICU, APACHE II score [13], length of stay in hospital, and outcome. Admissions were categorised into diagnostic groups: multiple trauma, sepsis, respiratory, gastrointestinal, cardiovascular, and other.

The design of the study was approved by the Committee for Ethical Research at the University of Health in Linköping. Eligible patients consented to participate in the study.

\section{Participants}

A total of 1,625 patients met the inclusion criteria. Of these, 911 patients answered the questionnaire at 6 months and are used in the baseline comparisons. In order to achieve comparability with the reference group, 188 patients were excluded because they were older then 74 years of age, the upper age limit for the sample from the reference group. Of the patients between 18 and 74 years old, 723 responded to the first inquiry at 6 months and 497 also responded at 12 months, and they then became the study group and are used in the comparisons with the reference group (Figure 1).

For the reference group, data from a public health survey of the county of Östergötland (the area in which the university hospital and one of the general hospitals is situated, adjacent to the county where the second general hospital is located) were used for comparison of sleep disturbances, concurrent disease and HRQoL. Questionnaires were initially sent out to 10,000 people. After two reminders, 6,093 (61\%) had responded [14].

\section{Questionnaires}

A set of structured questionnaires with information about the study and a request to participate were sent to the surviving patients 6 and 12 months after their discharge from hospital. The questionnaire contained questions about the patients' background data, including concurrent disease (self-reported diagnosis). The questionnaire asked 'Do you have any of the following illnesses and have had it for more than 6 months before the intensive care period with the pre-specified alternatives: cancer; diabetes; heart failure; asthma or allergy; rheumatic; gastrointestinal; blood; kidney; psychiatric; neurological disease; thyroid or any other metabolic disturbance, or other long-term illness?' (Table 1).

The questionnaire to the reference group also included, apart from questions on background characteristics, questions about health problems - including sleep and HRQoL (Medical Outcomes Study 36-item Short-form Health Survey (SF-36)). 


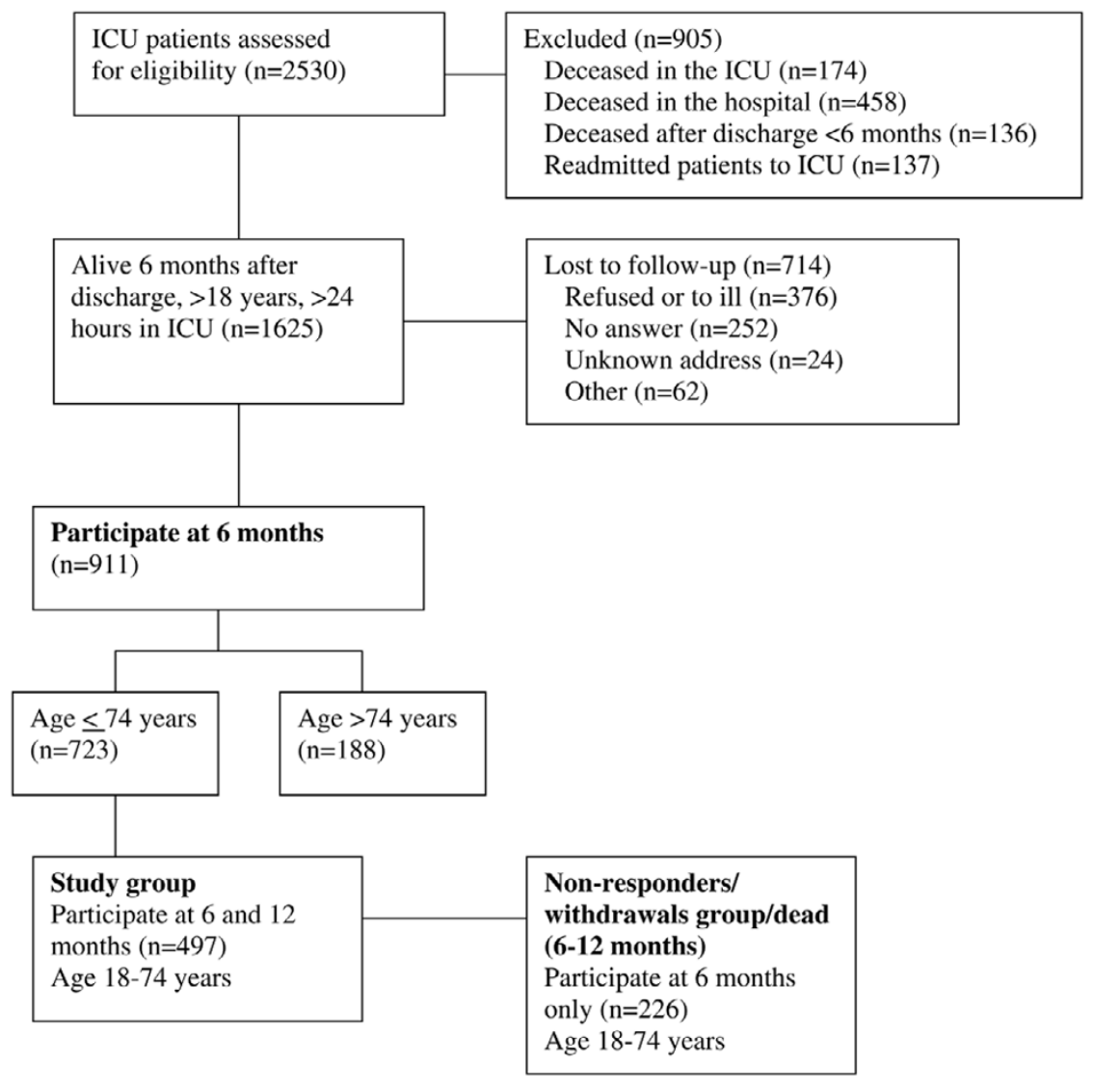

Algorithm of patients who were and were not included in the sleep disturbance study. All patients that responded at 6 months were used in baseline comparisons, whereas patients that responded both at 6 and 12 months and were younger than 75 years old were used in comparison with the reference group. ICU, intensive care unit.

\section{Instruments}

\section{Sleep disturbance}

The questions were taken from the Swedish version of the Basic Nordic Sleep Questionnaire [15]. The instrument has been shown to be valid $[15,16]$.

Three questions included in the Basic Nordic Sleep Questionnaire were used: 'Were there difficulties in falling asleep?' 'What was the quality of sleep like?' 'Was there a difference between the reported need for sleep and that achieved?' These questions were also used in the public health survey. To the second question above ('What was the quality of sleep like?'), yet another, single nonvalidated question [17] was added asking about the quality of sleep prior to the ICU stay. This question was only asked of the ICU group. The sleep instruments used in the study are presented in Additional file 1.

\section{Health-related quality of life}

The SF-36 was chosen for the evaluation of HRQoL $[18,19]$. The instrument is internationally well known and has often been used [20]. The SF-36 has previously been applied in intensive care $[4,21,22]$, and has recently been recommended as one of the best-suited instrument for measuring HRQoL in trials in critical care [23].

The SF-36 has been translated into Swedish and validated in a representative sample [24]. The survey has 36 questions and generates a health profile of eight subscale scores: physical functioning, role limitations caused by physical problems, bodily pain, general health, vitality, social functioning, role limitations due to emotional problems, and mental health [18,24]. The scores on all subscales are transformed to a scale ranging from 0 (the worst score) to 100 (best score).

\section{Statistical analysis}

Data are presented descriptively using parametric statistics (mean, 95\% confidence intervals, and one-way analysis of variance) and nonparametric statistics (Pearson's chi-square test and Kruskal-Wallis test). Logistic regression analysis, adjusted for sex, age, and concurrent disease, was used to evaluate the difference between the patients and the reference groups as appropriate. Logistic regression was also used to evaluate the independent effects of sex, age, concur 
Critical Care Vol 12 No 4 Orwelius et al.

Table 1

Characteristics of patients in the study group (6 and 12 months), in the nonresponders/withdrawals at 12 months group, and in the reference group

\begin{tabular}{|c|c|c|c|c|c|}
\hline & Study group $(n=497)$ & $\begin{array}{l}\text { Nonresponders/withdrawals group } \\
(\mathrm{n}=226)\end{array}$ & $P$ value $a$ & Reference group $(n=6093$ ) & $P$ value $b$ \\
\hline Sex (male/female) & $274 / 223$ & $136 / 90$ & 0.23 & $2822 / 3271$ & $<0.0001$ \\
\hline Age (years) & $52.4(15.7)$ & $52.5(16.1)$ & 0.97 & $46.4(15.1)$ & $<0.0001$ \\
\hline Marital status & & & 0.09 & & 0.006 \\
\hline Married & $327(67)$ & $130(59)$ & & $4484(74)$ & \\
\hline Single & $135(28)$ & 79 (35) & & $1334(22)$ & \\
\hline Widow/widower & $27(15)$ & $13(6)$ & & $274(4) \mathrm{c}$ & \\
\hline Children at home $<19$ years & $116(24)$ & $40(18)$ & 0.08 & & \\
\hline Born in Sweden & $454(92)$ & $201(89)$ & 0.26 & $5569(91)$ & 0.74 \\
\hline Education & & & & & $<0.0001$ \\
\hline Compulsory school & $166(34)$ & $84(38)$ & 0.35 & $1785(29)$ & \\
\hline High school/university & $121(25)$ & $52(23)$ & 0.78 & $1371(22)$ & \\
\hline Employment before ICU stay & & & 0.04 & & $<0.0001$ \\
\hline Employed & $237(50)$ & $103(48)$ & & 3589 (59) & \\
\hline Retired & $192(41)$ & $83(39)$ & & $1145(19)$ & \\
\hline Student & $20(4)$ & $6(3)$ & & $402(7)$ & \\
\hline Other & $21(5)$ & $23(10)$ & & $957(16)^{d}$ & \\
\hline 6 months after ICU stay & & & 0.31 & & \\
\hline Employed & $201(44)$ & $70(35)$ & & & \\
\hline Retired & $206(45)$ & $101(51)$ & & & \\
\hline Student & $15(3)$ & $9(4)$ & & & \\
\hline Other & $36(8)$ & $20(10)$ & & & \\
\hline Sick leave before ICU stay & $70(14)$ & $29(13)$ & 0.46 & & \\
\hline Reported sick $<100 \%$ & $13(3)$ & $8(3)$ & & & \\
\hline Reported sick $100 \%$ & $50(10)$ & $18(3)$ & & & \\
\hline 6 months after ICU & $121(24)$ & $59(26)$ & 0.70 & & \\
\hline Reported sick $<100 \%$ & $20(4)$ & $8(3)$ & & & \\
\hline Reported sick $100 \%$ & $94(19)$ & $48(21)$ & & & \\
\hline Concurrent disease ${ }^{e}$ & $342(69)$ & $179(79)$ & 0.005 & $3095(51)$ & $<0.0001$ \\
\hline Cancer & $48(10)$ & $32(18)$ & & & \\
\hline Diabetes & $57(11)$ & $29(16)$ & & & \\
\hline Cardiovascular & $83(17)$ & $36(20)$ & & & \\
\hline Gastrointestinal & $50(10)$ & $25(14)$ & & & \\
\hline Miscellaneous & $322(65)$ & $168(74)$ & & & \\
\hline
\end{tabular}

Not all patients answered all questions. Data presented as $\mathrm{n}(\%)$ of totals, except age as mean (standard deviation). Bold data is on significant level. aStudy group compared with nonresponders/withdrawals at 12 months (Fisher's exact test or Pearson chi-square test). bReference group compared with study group (Fisher's exact test or Pearson chi-square test). IIn public health survey, the category variable was other. ${ }^{\mathrm{d}}$ Including sick leave. ePatients can have more than one disease. 
rent disease, APACHE II scores on admission, length of stays in ICU and in hospital, and diagnoses on admission on sleep disturbances among the patients and the relation between sleep disturbances and HRQoL.

Sleep disturbances and HRQoL among the ICU patients were compared with those reported by the sample of the general population of the county of Östergötland, who had answered an independent mail survey in 1999. There were three questions in this mail survey that overlapped with questions on sleeping problems in our study. The answers were dichotomised and compared as follows: the severity of difficulties in falling asleep at least weekly rather than less than weekly; poor quality of sleep or worse compared with good or better sleep; and time slept less than required compared with time slept equal to or more than required.

Interactions were also assessed. As eight different HRQoL measures were used (the SF-36 eight subscales), the number of comparisons involved became rather large. No adjustment for multiple comparisons was done. Findings were considered significant, however, only if there were concurrent changes in several related variables.

The Statistical Package for the Social Sciences (version 15.0; SPSS Inc., Chicago, IL, USA) was used for the statistical analyses. $P<0.05$ was accepted as significant.

\section{Results}

\section{Characteristics of patients}

The characteristics of the patients in the study group, in the nonresponders/withdrawals group at 12 months, and in the reference group are presented in Table 1.

The patients in the study group $(n=497)$ were less out of work and were less likely to have concurrent diseases than the patients in the nonresponding/withdrawals group $(n=226)$. Compared with the reference group, the patients in the study group were more likely to be men, to be older, to have different marital status and education status, and to be retired. The study group patients also more often had concurrent diseases in the same comparison (69\% versus 51\%).

There were no significant differences between the study group and the nonresponders/withdrawals group in the APACHE score $(P=0.106)$, the length of stay in the ICU $(P=0.130)$ or the length of stay in the hospital $(P=0.474)$, or in the diagnoses recorded at admission $(P=0.899)$, the most common of which was gastrointestinal disease (data not shown).

\section{Sleep disturbances}

In comparing the quality of sleep pattern prior to the ICU stay with that 6 months after the ICU/hospital discharge, the prevalence of self-reported quality of sleep did not change from the pre-ICU period to the post-ICU period (Table 2).
Table 2

Comparison of quality of sleep before the intensive care unit (ICU) period and 6 months after ICU period $(n=911)$

\begin{tabular}{lll}
\hline \multirow{2}{*}{ Before ICU staya } & \multicolumn{2}{l}{6 months after ICU stayb } \\
\cline { 2 - 3 } & Good & Bad \\
\hline Good & $459(70)$ & $60(9)$ \\
Bad & $56(8)$ & $85(13)$ \\
\hline
\end{tabular}

Seventy-two percent of the patients answered the questions (a) Rate your overall sleep quality before the intensive care period, and (b) Rate your overall sleep quality during the last month. Data presented as number (\%) of totals.

The study group had more difficulty in falling asleep, had poorer quality of sleep and slept for shorter periods than the reference group (38\% versus $13 \%, 20 \%$ versus $12 \%$ and $61 \%$ versus $55 \%$, respectively). Apart from difficulties falling asleep, these differences were minor after adjusting for sex, age and concurrent disease. Little or no improvement was seen over time for the ICU group in falling asleep, quality of sleep, and sleep deficit (data not shown). When we compared the previously healthy in the study group with those with concurrent diseases, difficulty in falling asleep and quality of sleep increased and decreased by almost $50 \%$, respectively. When the study group with concurrent disease was compared with the corresponding people in the reference group, the quality of sleep and amount of sleep deficit were roughly the same (Table 3). For the hospitalised patients with an ICU stay, the clinical data did not differ for the two groups presenting sleep disturbances at 6 months and presenting no sleep disturbances at 6 months $(n=911)$ (Table 4$)$.

\section{Risk factors for sleep disturbances}

Our main findings were that the study group was more likely to have disturbed sleep at both 6 and 12 months (odds ratio = $3.61,95 \%$ confidence interval $=2.93$ to 4.46 at 6 months; and odds ratio $=3.62,95 \%$ confidence interval $=2.93$ to 4.47 at 12 months for difficulties in falling asleep), and that women had a tendency to have more disturbed sleep at both 6 and 12 months than men (odds ratio $=1.13,95 \%$ confidence interval $=0.98$ to 1.30 at 6 months; and odds ratio $=1.16,95 \%$ confidence interval $=1.00$ to 1.34 at 12 months for difficulties in falling asleep). Concurrent diseases were strongly associated with all three types of sleep disturbances (odds ratio $=3.34$, $95 \%$ confidence interval $=2.84$ to 3.94 at 6 months; and odds ratio $=3.29,95 \%$ confidence interval $=2.80$ to 3.88 at 12 months for difficulties in falling asleep).

\section{Impact of different factors on sleep disturbances}

Concurrent disease was strongly associated with two complaints of sleep disturbances (difficulties in falling asleep and poor quality of sleep) $(P<0.001)$ (Table 5$)$. For the ICUrelated factors (APACHE II, length of stay in ICU or in hospital, and admission diagnoses), there were no associations with any of the sleep disturbances. Mechanical ventilation had no 
Critical Care Vol 12 No 4 Orwelius et al.

Table 3

Sleep disturbances in patients $(n=497)$ and in the reference group within the total patients and patients with or without concurrent disease

\begin{tabular}{|c|c|c|c|c|c|c|c|c|c|}
\hline & \multicolumn{3}{|l|}{ Total patients } & \multicolumn{3}{|c|}{ Concurrent disease patients } & \multicolumn{3}{|c|}{ Previously healthy patients } \\
\hline & ICU patients & $\begin{array}{l}\text { Reference } \\
\text { group }\end{array}$ & $P$ value & ICU patients & $\begin{array}{l}\text { Reference } \\
\text { group }\end{array}$ & $P$ value & ICU patients & $\begin{array}{l}\text { Reference } \\
\text { group }\end{array}$ & $P$ value \\
\hline \multicolumn{10}{|l|}{ Difficulties in falling asleep } \\
\hline Never or $<1$ times/week & $62 \%$ & $87 \%$ & $<0.001$ & $55 \%$ & $81 \%$ & $<0.001$ & $78 \%$ & $94 \%$ & $<0.001$ \\
\hline $\begin{array}{l}\text { From } 1 \text { to } 2 \text { days/week } \\
\text { to daily or almost daily }\end{array}$ & $38 \%$ & $13 \%$ & & $45 \%$ & $19 \%$ & & $22 \%$ & $6 \%$ & \\
\hline Total $(n)$ & 472 & 5826 & & 326 & 2955 & & 146 & 2871 & \\
\hline \multicolumn{10}{|l|}{$\begin{array}{l}\text { Sleep quality during the } \\
\text { past month }\end{array}$} \\
\hline $\begin{array}{l}\text { Neither good nor bad, } \\
\text { good or very good }\end{array}$ & $80 \%$ & $88 \%$ & $<0.001$ & $77 \%$ & $81 \%$ & 0.080 & $88 \%$ & $95 \%$ & 0.001 \\
\hline $\begin{array}{l}\text { Quite bad, poor or very } \\
\text { poor }\end{array}$ & $20 \%$ & $12 \%$ & & $23 \%$ & $19 \%$ & & $12 \%$ & $5 \%$ & \\
\hline Total $(n)$ & 473 & 6047 & & 326 & 3074 & & 147 & 2973 & \\
\hline \multicolumn{10}{|l|}{ Sleep deficit } \\
\hline $\begin{array}{l}\text { Need for sleep higher } \\
\text { than habitual sleep }\end{array}$ & $61 \%$ & $55 \%$ & 0.034 & $64 \%$ & $59 \%$ & 0.196 & $56 \%$ & $51 \%$ & 0.310 \\
\hline $\begin{array}{l}\text { Need for sleep equal or } \\
\text { less to habitual sleep }\end{array}$ & $39 \%$ & $45 \%$ & & $36 \%$ & $41 \%$ & & $44 \%$ & $49 \%$ & \\
\hline Total $(n)$ & 279 & 5605 & & 192 & 2825 & & 88 & 2780 & \\
\hline
\end{tabular}

Data presented as the percentage of the intensive care unit (ICU) study group ( $n=497)$ (responding at both 6 and 12 months) at the 6-month measure, Not all patients answered the questions.

Table 4

Clinical characteristics on admission of all patients with and without sleep disturbances $(\mathrm{n}=\mathbf{9 1 1})$

\begin{tabular}{|c|c|c|c|}
\hline & Sleep disturbances $(n=419)$ & No sleep disturbances $(n=471)$ & $P$ value \\
\hline Age (years) ${ }^{a}$ & $55.7(18.4)$ & $60.2(18.0)$ & 0.419 \\
\hline Gender (male/female) (\%) & $44.9 / 50.0$ & $55.1 / 50.0$ & 0.077 \\
\hline APACHE II score ${ }^{b}$ & $15.2(14.4$ to 16.0$)$ & $15.7(15.0$ to 16.4$)$ & 0.525 \\
\hline Duration of stay in ICU (hours)c & $122.7(55.0)$ & $126.0(60.3)$ & 0.878 \\
\hline Duration of stay in hospital (days)c & $15.2(9.0)$ & $15.2(9.0)$ & 0.739 \\
\hline Diagnosis on admissiond & & & 0.067 \\
\hline Multiple trauma & $49(11.7)$ & $51(10.8)$ & \\
\hline Sepsis & $38(9.1)$ & $38(8.1)$ & \\
\hline Gastrointestinal & $80(19.1)$ & $101(21.4)$ & \\
\hline Respiratory & $84(20.0)$ & $98(20.8)$ & \\
\hline Cardiovascular & $29(6.9)$ & $57(12.1)$ & \\
\hline Miscellaneous & 139 (33.2) & $126(26.8)$ & \\
\hline
\end{tabular}

Data are given as amean (standard deviation), bmean (95\% confidence interval), cmean and median (standard deviation) or dn (\%). APACHE II, Acute Physiology and Chronic Health Evaluation. 
Impact of different factors on sleep disturbances at 6 months $(n=911)$

\begin{tabular}{|c|c|c|c|c|c|c|c|c|c|c|}
\hline & \multirow[b]{2}{*}{$\mathrm{n}$} & \multicolumn{3}{|c|}{ Difficulties in falling asleep } & \multicolumn{3}{|c|}{ Poor quality of sleep } & \multicolumn{3}{|c|}{ Sleep deficit } \\
\hline & & OR & $\mathrm{Cl} 95 \%$ for OR & $P$ value & OR & $\mathrm{Cl} 95 \%$ for OR & $P$ value & OR & $\mathrm{Cl} 95 \%$ for OR & $P$ value \\
\hline Concurrent disease & & 2.32 & 1.67 to 3.23 & $<0.001$ & 2.51 & 1.62 to 3.89 & $<0.001$ & 1.14 & 0.76 to 1.72 & 0.52 \\
\hline \multicolumn{11}{|l|}{ APACHE II score } \\
\hline 0 to 15 & 491 & 1.00 & & 0.06 & 1.00 & & 0.80 & 1.00 & & 0.63 \\
\hline 16 to 25 & 315 & 0.61 & 0.39 to 0.95 & & 0.85 & 0.49 to 1.44 & & 1.35 & 0.71 to 2.55 & \\
\hline 26 to 43 & 105 & 0.78 & 0.49 to 1.23 & & 0.83 & 0.48 to 1.45 & & 1.21 & 0.63 to 2.32 & \\
\hline \multicolumn{11}{|l|}{ LoS in ICU } \\
\hline$<37$ hours & 221 & 1.00 & & 0.14 & 1.00 & & 0.70 & 1.00 & & 0.33 \\
\hline 38 to 52 hours & 201 & 0.98 & 0.66 to 1.45 & & 1.19 & 0.74 to 1.91 & & 1.39 & 0.80 to 2.40 & \\
\hline 53 to 144 hours & 275 & 0.64 & 0.43 to 0.97 & & 0.89 & 0.54 to 1.47 & & 0.92 & 0.53 to 1.59 & \\
\hline$>144$ hours & 214 & 0.85 & 0.58 to 1.23 & & 0.99 & 0.63 to 1.57 & & 0.90 & 0.54 to 1.50 & \\
\hline \multicolumn{11}{|l|}{ LoS in hospital } \\
\hline$<5$ days & 281 & 1.00 & & 0.75 & 1.00 & & 0.99 & 1.00 & & 0.57 \\
\hline 6 to 13 days & 320 & 1.00 & 0.71 to 1.41 & & 0.97 & 0.64 to 1.46 & & 1.03 & 0.65 to 1.62 & \\
\hline$>13$ days & 310 & 0.90 & 0.64 to 1.25 & & 0.99 & 0.66 to 1.47 & & 1.25 & 0.80 to 1.95 & \\
\hline \multicolumn{11}{|c|}{ Diagnosis at admission } \\
\hline Multiple trauma & 102 & 1.00 & & 0.59 & 1.00 & & 0.14 & 1.59 & & 0.17 \\
\hline Sepsis & 78 & 1.61 & 0.85 to 3.03 & & 2.13 & 0.93 to 4.87 & & 0.98 & 0.44 to 2.20 & \\
\hline Gastrointestinal & 188 & 1.33 & 0.69 to 2.56 & & 2.62 & 1.13 to 6.05 & & 1.99 & 0.75 to 5.27 & \\
\hline Respiratory & 185 & 1.19 & 0.69 to 2.08 & & 1.31 & 0.60 to 2.85 & & 1.35 & 0.65 to 2.81 & \\
\hline Cardiovascular & 88 & 1.42 & 0.84 to 2.40 & & 1.97 & 0.95 to 4.10 & & 1.83 & 0.91 to 3.69 & \\
\hline Miscellaneous & 270 & 1.10 & 0.63 to 1.92 & & 1.59 & 0.74 to 3.40 & & 1.89 & 0.90 to 3.97 & \\
\hline
\end{tabular}

Impact determined using logistic regression univariate analysis. Intensive care unit (ICU) patients only. The results are adjusted for age and sex. APACHE, Acute Physiology and Chronic Health Evaluation; Cl, confidence interval; LoS, length of stay; OR, odds ratio. Bold data is on significant level.

significant influence on sleep disturbances (data not shown) $(P=0.779$ for difficulties in falling asleep, $P=0.801$ for poor quality of sleep, $P=0.512$ for sleep deficit).

\section{Health-related quality of life}

Baseline SF-36 data for the ICU group are provided in Figure 2. The only correlation in all three aspects of sleep disturbances was found for mental health and bodily pain. Difficulty in falling asleep had an impact on general health. Poor quality of sleep affected vitality. Sleep deficit had an impact on role limitations due to physical problems (Table 6). Increasing age was a risk factor for decreased HRQoL (data not shown).

\section{Discussion}

Our overall aim was to examine the prevalence of long-term sleep disturbances - interpreted as difficulties in falling asleep, poor quality of sleep and sleep deficit - for ICU patients 6 and 12 months after their discharge from the ICU and from the hospital. For the study we used large patient numbers for both the study group and the reference group. The new and important findings are that sleep disturbances are common (up to $38 \%$ affected and without improvement at 12 months) after discharge from the ICU and from the hospital. The change in the quality of sleep pattern, however, for the hospitalised patients with an ICU stay was found minor both when comparing patterns prior to ICU stay with after ICU stay as well as patterns 6 months after ICU stay with 12 months after ICU stay. Concurrent disease is the most important factor for sleep disturbances.

\section{Sleep disturbances}

There are few generally accepted definitions or corresponding reference data about sleep disturbances, so the criteria and the reference group must be chosen carefully. We chose the Swedish version of the Basic Nordic Sleep Questionnaire as it has been shown to be practical and valid $[15,16]$ and had 
Figure 2

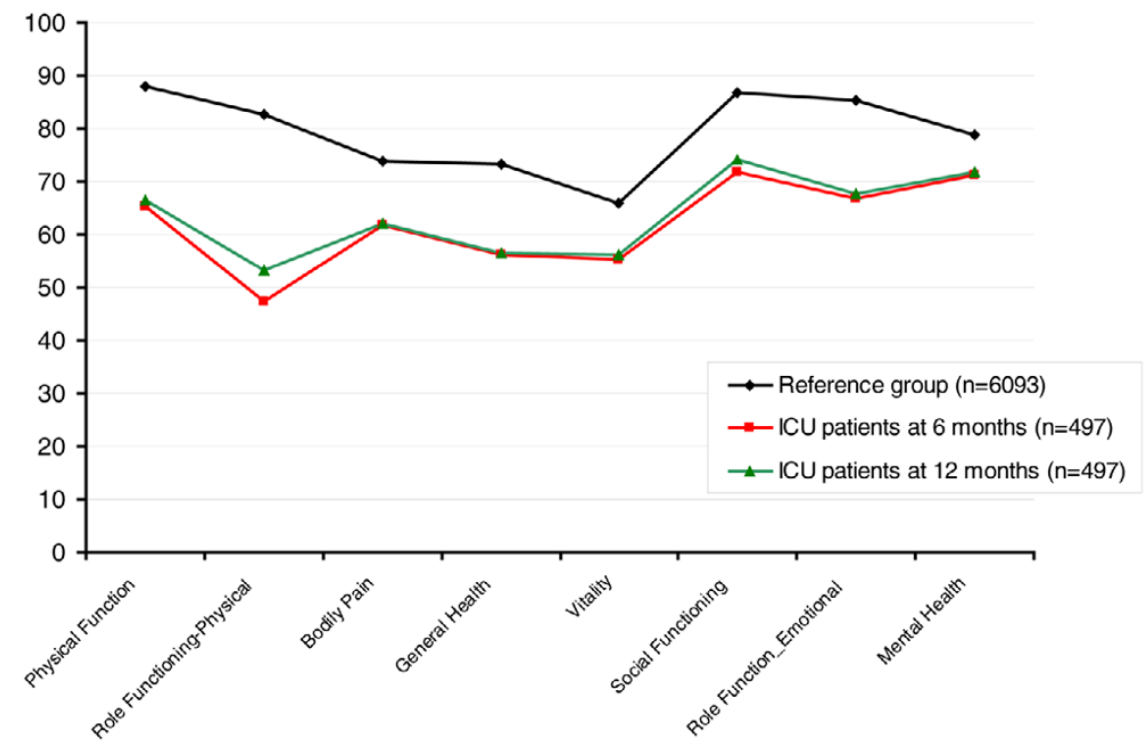

Medical Outcomes Study 36-item Short-form Health Survey results. The Medical Outcomes Study 36-item Short-form Health Survey results are presented for the reference group compared with the intensive care unit (ICU) group that participated at 6 and 12 months. Data presented as the mean.

also been used to collect the data of the reference group [14]. Our reference group was a large patient group from the referral area of the three hospitals that had also reported similar conditions to those collected for the ICU patient group [4].

Importantly, it was found that few of the patients changed their quality of sleep pattern when comparing patterns prior to the stay with those after the ICU stay and the hospital stay. Also interesting is that one-half of the group that changed their sleep quality showed an improvement. These data suggest that there seem to be only minor changes in sleep quality after a critical care period.
Difficulties in falling asleep and the quality of sleep were affected and remained altered at 12 months in $38 \%$ and $20 \%$ of former ICU patients, respectively. After adjusting for age and sex, however, it was found that concurrent disease had more effect on the sleep patterns than any other factor.

Like those in the study group, women in the reference group reported more sleep disturbances than men (19\% and 16\%, respectively) [14]. The predisposition of women for sleep dis-

Table 6

Association between sleep disturbances and health-related quality of life at 6 months $(n=911)$

\begin{tabular}{|c|c|c|c|c|c|c|c|c|c|}
\hline \multirow[b]{2}{*}{ Predictor } & \multicolumn{3}{|c|}{ Difficulties in falling asleep } & \multicolumn{3}{|c|}{ Poor quality of sleep } & \multicolumn{3}{|c|}{ Sleep deficit } \\
\hline & OR & $95 \% \mathrm{Cl}$ for OR & $P$ value & OR & $95 \% \mathrm{Cl}$ for OR & $P$ value & OR & $95 \% \mathrm{Cl}$ for OR & $P$ value \\
\hline Physical functioning & 1.0 & 0.93 to 1.06 & 0.887 & 1.08 & 0.99 to 1.16 & 0.076 & 1.04 & 0.96 to 1.13 & 0.322 \\
\hline Role limitations due to physical problems & 1.01 & 0.96 to 1.06 & 0.700 & 1.04 & 0.98 to 1.10 & 0.188 & 1.08 & 1.02 to 1.14 & 0.011 \\
\hline Bodily pain & 0.90 & 0.85 to 0.96 & 0.001 & 0.89 & 0.83 to 0.96 & 0.002 & 0.88 & 0.81 to 0.95 & 0.001 \\
\hline General health & 0.84 & 0.77 to 0.92 & $<0.001$ & 0.90 & 0.80 to 1.02 & 0.089 & 0.93 & 0.83 to 1.04 & 0.212 \\
\hline Vitality & 0.95 & 0.86 to 1.05 & 0.318 & 0.81 & 0.72 to 0.91 & $<0.001$ & 0.99 & 0.88 to 1.12 & 0.873 \\
\hline Social functioning & 1.02 & 0.95 to 1.10 & 0.598 & 1.00 & 0.91 to 1.10 & 0.993 & 1.02 & 0.92 to 1.12 & 0.759 \\
\hline $\begin{array}{l}\text { Role limitations due to emotional } \\
\text { problems }\end{array}$ & 0.98 & 0.94 to 1.02 & 0.364 & 0.95 & 0.90 to 1.00 & 0.056 & 0.99 & 0.93 to 1.05 & 0.660 \\
\hline Mental health & 0.80 & 0.74 to 0.87 & $<0.001$ & 0.80 & 0.72 to 0.89 & $<0.001$ & 0.89 & 0.81 to 0.98 & $<0.001$ \\
\hline
\end{tabular}

Association determined using multiple logistic regression analysis, final model. Adjusted for age and gender. Odds ratio (OR) with a 10-unit change. Intensive care unit patients only. $\mathrm{Cl}$, confidence interval. 
turbances and the extent of sleep disturbances reported in a Swedish population have previously been confirmed by Fahlen and colleagues [25]. Their study of a general population showed that $23 \%$ of the women were affected compared with $14 \%$ of men.

It is evident that the long-term sleep disturbances in general for the ICU group are minor at 6 and 12 months, if concurrent disease is excluded from the analysis. When we subtracted the patients who had concurrent disease, we found that there was a $50 \%$ reduction in sleep disturbances for the remaining study group. Patients in the ICU are likely to have serious concurrent diseases [4]. Our prestudy hypothesis was that patients in the ICU have more sleep disturbances caused by both the period of critical care and the presence of concurrent diseases. Chronic diseases are known to affect sleeping patterns, and the prevalence of sleep disturbances in such a group in the general population is high [26]. We also found this in the present study, where the overall and most important cause of sleep disturbances was concurrent disease.

We found no relation when we assessed the possible effect of the period of ICU care (APACHE score, length of stay, admission diagnosis, and time on the ventilator) on the sleeping patterns after critical illness. This is in line with the findings of Freedman and colleagues, who found no significant correlations of perceived ICU sleep disturbances and length of stay in ventilated patients or nonventilated patients [17]. Our main finding is therefore that sleeping patterns are altered 6 and 12 months afterwards for people who have been in the ICU, but this is most probably the result of the presence of other diseases rather than of factors related to the care in the ICU itself.

The lack of improvement over time further reduces the likelihood that the period in the ICU contributed appreciably to any sleep disturbances after discharge.

\section{Health-related quality of life}

For the study group we found significantly reduced HRQoL in the dimensions of role limitations due to physical problems, bodily pain, general health, vitality, and mental health measured by the SF-36. These changes correlated only in some aspects to the sleep disturbances.

Comparing our results with other studies is difficult, as we found only one study that had been designed to assess the impact of sleep disturbances on HRQoL after intensive care. In that study, Granja and colleagues used the EuroQol 5D as a measure of HRQoL 6 months after an intensive care stay [27]. They found that sleep disturbances were significantly associated with a worse HRQoL in all dimensions of the EuroQol 5D. Granja and colleagues did not adjust for concurrent disease but $59 \%$ of their patients had chronic diseases, and $41 \%$ of these reported sleep problems.
Katz and McHorney also assessed the prevalence of insomnia and its impact on HRQoL in patients with chronic illness [12]. They defined insomnia as difficulty in initiating or maintaining sleep; they also showed a close relation between insomnia and chronic illness. Patients with insomnia were independently associated with worsened HRQoL, particularly with worsened mental health, vitality, and general health.

We found that all three types of sleep disturbances affected mental health and bodily pain. Léger and colleagues also found an association between insomnia and bodily pain in their study of HRQoL and insomnia in a general population [28]. They concluded, however, that it is possible for poor sleep to increase the sensitivity to pain. In another study, Schubert and colleagues found that insomnia was common among older adults and that it was then associated with decreased HRQoL [29].

\section{Limitations of the study}

One limitation of the present study is that, in order to evaluate the extent of sleep disturbances in the patient population, we have chosen a control group among inhabitants of the uptake areas of the three hospitals. It may be suggested that a hospitalised group would be a better control group by better picturing the comorbidities. Knowing the heterogeneity of the ICU population, it is very difficult to pick an adjusted cohort containing the specific characteristics of our ICU population, especially as large numbers are needed. We have chosen a more practical solution - that is, to address a very large number of habitants in the area. In order to adjust the individuals in this cohort to concurrent disease, they were asked to provide information on factors believed to be important for their health. The individuals have provided diagnoses and symptoms; the latter was converted to diagnoses by two medicine doctors [4]. We have thereafter tried to make a comparison between the patients and this adjusted cohort. As this group is only an attempt to compensate for not having the sleep disturbances data prior to the ICU stay, it is a shortcoming of the present study.

Secondly, the ICU length of stay is short in the present study. Although the length of stay is comparable with the length of stay presented in the Swedish ICU registry, it may be significantly shorter than seen for other ICUs. This precludes its generalisability for such settings.

There is limited information on the reliability of and validity of sleep questionnaires in the critical care setting. There is also no consensus on which protocol to use. Further, there is the risk of recall bias - although this bias can be argued to be minor as there are 6 months between the measurements. These three listed factors may also hamper the evaluation of the data. 
Fourthly, it is important for the strengths of the conclusions made in the present paper to note that there is a significant loss to follow-up. The low response rate, however, is in the range commonly seen in similar studies.

Fifth, an important influence on sleep disturbances is the degree of substance use or misuse [30]. We did not ask the patients specifically if they misused alcohol or other substances or drugs. This may have influenced our findings if substance misuse had been higher in the ICU group than in the reference group, as such effects may lead to a misleadingly high rate of sleep disturbances [30]. As we were unable to find any effects beyond those of age, sex, and concurrent disease, however, such factors may be claimed less important. Furthermore, the extent of sedation during the ICU period may also be claimed as an important factor for our outcome. Using the time on ventilator as a surrogate measure of the extent of sedation, however, we were unable to find any correlations to sleep disturbances.

Another limitation in our study is that we did not assess posttraumatic stress disorder. Complaints of sleep disturbances are common among patients with post-traumatic stress disorder, and the disorder is common in patients who have been treated in the ICU [31]. As the effects beyond the factors examined and adjusted for (age, sex, concurrent disease and ICU-related factors) were minor, however, we think the overall effect of post-traumatic stress disorder must also be limited. In addition, Klein and colleagues demonstrated in their study of motor-vehicle-collision victims that altered perception rather than sleep disturbance per se may be the key problem in posttraumatic stress disorder [7].

Finally, effects of cognitive function or dysfunction may have affected the results and their interpretation. Unfortunately, the present study did not assess this.

\section{Conclusion}

Although the change in quality of sleep prior to the ICU and hospital stays compared with that after the ICU and hospital stays seem to be minor, we found a high prevalence of sleep disturbances (difficulties in falling asleep, quality of sleep and sleep deficit) for the patient long term after discharge from the ICU. Interestingly, these sleep disturbances were not affected by ICU factors but were instead mostly due to concurrent diseases. It is thus important to include assessment of concurrent diseases in sleep-related research for the ICU population.

\section{Competing interests}

The authors declare that they have no competing interests.

\section{Authors' contributions}

LO designed the study, performed and interpreted the data analysis, and drafted the manuscript. AN and FS designed the study, interpreted the data analysis, and drafted the manu-

\section{Key messages}

- Changes in quality of sleep prior to compared with after stays in the ICU and in the hospital seem to be minor.

- $\quad$ Sleep disturbances are common after critical care at 6 months (from $5 \%$ to $25 \%$ more common than the general population), with little or no improvement over time.

- Intensive-care-related factors do not seem to influence sleep at 6 and 12 months after ICU stay, whereas concurrent disease is the main explanation for the sleep problems registered.

script. PN and UE-G revised the manuscript. All authors have read and approved the final manuscript.

\section{Additional files}

The following Additional files are available online:

\section{Additional file 1}

An Excel file presenting the sleep instruments used in the present study.

See http://www.biomedcentral.com/content/ supplementary/cc6973-S1.xls

\section{Acknowledgements}

The authors thank Ebba Lunden, administrative assistant, Eva Simonsson and Carl Bäckman CCRN for the collection of data, Olle Eriksson for statistical advice, and Mary Evans for the English revision of the manuscript. They are also grateful to the Linquest Group at the Centre for Public Health at the County Council of Östergötland for providing access to the data for the reference group. The present study is supported, in part, by a grant from The Health Research Council in the South-East of Sweden (FORSS) F2002-207, F2004-204, FORSS5515 , and the County Council of Östergötland, Sweden.

\section{References}

1. Jones C, Griffiths RD, Humphris G, Skirrow PM: Memory, delusions, and the development of acute posttraumatic stress disorder - related symptoms after intensive care. Crit Care Med 2001, 29:573-580.

2. Granberg A, Bergbom Engberg I, Lundberg D: Patients'experience of being critically ill or severely injured and cared for in an intensive care unit in relation to the ICU syndrome. Intensive Crit Care Nurs 1998, 14:294-307.

3. Dowdy D, Eid M, Sedrakyan A, Mendez-Tellez P, Pronovost P, Herridge $M$, Needham D: Quality of life in adult survivors of critical illness: a systematic review of the literature. Intensive Care Med 2005, 31:611-620.

4. Orwelius L, Nordlund A, Edéll-Gustafsson U, Simonsson E, Nordlund $P$, Kristenson $M$, Bendtsen $P$, Sjöberg $F$ : Role of preexisting disease in patients' perceptions of health-related quality of life after intensive care. Crit Care Med 2005, 33:1557-1564.

5. Wiley J, Camacho T: Lifestyle and future health; evidence from the Alameda County Study. Prev Med 1980, 9:1-21.

6. Chishti A, Batchelor A, Bullock R, Fulton B, Gascoigne A, Baudouin S: Sleep-related breathing disorders following discharge from intensive care. Intensive Care Med 2000, 26:426-433 
7. Klein E, Koren D, Arnon I, Lavie P: Sleep complaints are not corroborated by objective sleep measures in post-traumatic stress disorder: a 1-year prospective study in survivors of motor vehicle crashes. J Sleep Res 2003, 12:35-41.

8. Cronin A, Keifer J, Davies M, King T, Bixler E: Postoperative sleep disturbance: influences of opioids and pain in humans. Sleep 2001, 24:39-44.

9. Rosenberg J: Sleep disturbances after non-cardiac surgery. Sleep Med Rev 2001, 5:129-137.

10. Zhang $B$, Wing $Y-K$ : Sex differences in insomnia: a meta-analysis. Sleep 2006, 29:85-93.

11. Leger D, Guilleminault C, Dreyfus JP, Delahaye C, Paillard M: Prevalence of insomnia in a survey of $12 \mathbf{7 7 8}$ adults in France. J Sleep Res 2000, 9:35-42.

12. Katz DA, McHorney CA: The relationship between insomnia and health-related quality of life in patients with chronic illness. J Fam Pract 2002, 51:229-235.

13. Knaus W, Draper E, Wagner D, Zimmerman J: APACHE II: a severity of disease classification system. Crit Care Med 1985, 13:818-829.

14. Ekberg $\mathrm{K}$, Noorlind Brage $\mathrm{H}$, Dastserri $\mathrm{M}$ : Report 00:1, Östgötens hälsa och miljö 2000 [Health and Environment 2000 in Östergötland] [in Swedish] Linköping, Sweden Centre for Public Health, County Council of Östergötland; 2000.

15. Partinen M, Gislason T: Basic Nordic Sleep Questionnaire (BNSQ): a quantitated measure of subjective sleep complaints. J Sleep Res 1995, 4:150-155.

16. Edéll-Gustafsson UM, Hetta JE: Fragmented sleep and tiredness in males and females one year after percutaneous transluminal coronary angioplasty (PTCA). J Adv Nurs 2001, 34:203-211.

17. Freedman NS, Kotzer N, Schwab RJ: Patient perception of sleep quality and etiology of sleep disruption in the intensive care unit. Am J Respir Crit Care Med 1999, 159:1155-1162.

18. Ware JE Jr, Sherbourne CD: The MOS 36-item short-form health survey (SF-36). I. Conceptual framework and item selection. Med Care 1992, 30:473-483.

19. McHorney CA, Ware JE Jr, Raczek AE: The MOS 36-Item ShortForm Health Survey (SF-36): II. Psychometric and clinical tests of validity in measuring physical and mental health constructs. Med Care 1993, 31:247-263.

20. Garratt A, Schmidt L, Mackintosh A, Fitzpatrick R: Quality of life measurement: bibliographic study of patient assessed health outcome measures. BMJ 2002 . doi: $10.1136 / \mathrm{bmj}$. 324.7351 .14171417$.

21. Eddleston JM, White P, Guthrie E: Survival, morbidity, and quality of life after discharge from intensive care. Crit Care Med 2000, 28:2293-2299.

22. Graf J, Koch M, Dujardin R, Kersten A, Janssens U: Health-related quality of life before, 1 month after, and 9 months after intensive care in medical cardiovascular and pulmonary patients. Crit Care Med 2003, 31:2163-2169.

23. Angus DC, Carlet J: Surviving intensive care: a report from the 2002 Brussels Roundtable. Intensive Care Med 2003, 29:368-377.

24. Sullivan M, Karlsson J, Ware JE Jr: The Swedish SF-36 health survey-I. Evaluation of data quality, scaling assumptions, reliability and construct validity across general populations in Sweden. Soc Sci Med 1995, 41:1349-1358.

25. Fahlen G, Knutsson A, Peter R, Ảkerstedt T, Nordin M, Alfredsson L, Westerholm P: Effort-reward imbalance, sleep disturbances and fatigue. Int Arch Occup Environ Health 2006, 79:371-378.

26. Kripke DF, Youngstedt SD, Elliott JA, Tuunainen A, Rex KM, Hauger RL, Marler MR: Circadian phase in adults of contrasting ages. Chronobiol Int 2005, 22:695-709.

27. Granja C, Lopes A, Moreira S, Dias C, Costa-Pereira A, Carneiro A: Patients' recollections of experiences in the intensive care unit may affect their quality of life. Crit Care 2005, 9:R96-R109.

28. Léger D, Scheuiermaier K, Philip P, Paillard M, Guilleminault C: SF-36: evaluation of quality of life in severe and mild insomniacs compared with good sleepers. Psychosom Med 2001, 63:49-55.

29. Schubert CR, Cruickshanks KJ, Dalton DS, Klein BEK, Klein R, Nondahl DM: Prevalence of sleep problems and quality of life in an older population. Sleep 2002, 25:889-893.
30. Frisk U, Nordström G: Patients sleep in an intensive care unit patients and nurses perception. Intensive Crit Care Nurs 2003 19:342-349.

31. Schelling G, Richter M, Roozendaal B, Rothenhausler H, Krauseneck T, Stoll C, Nollert G, Schmidt M, Kapfhammer H: Exposure to high stress in the intensive care unit may have negative effects on health-related quality-of-life outcomes after cardiac surgery. Crit Care Med 2003, 31:1971-1980. 